\title{
FURTHER OBSERVATIONS ON THE DETERMINATION OF CATECHOLAMINE METABOLITES IN TUMOURS OF SYMPATHETIC NERVOUS SYSTEM* ${ }^{*}$
}

\author{
BY \\ H. KÄSER, M. BETTEX and W. v. STUDNITZ \\ From the Department of Surgery, Paediatric Clinic and Institute for Clinical Protein Research, \\ University of Berne, Switzerland; Department of Clinical Chemistry, General Hospital, Malmö, \\ University of Lund, Sweden
}

In 1961 one of us (M.B.) reported our first results (Bettex and Käser, 1962) of vanillyl-mandelic acid (= 3-methoxy-4-hydroxymandelic acid, MHMA) determination in the urine of children with tumours of the sympathetic nervous system. It was recognized a few years ago (Armstrong and McMillan, 1957, 1959; Armstrong, McMillan and Shaw, 1957; Axelrod, Senoh and Witkop, 1958; Axelrod, Inscoe, Senoh and Witkop, 1958; Kirshner, Goodall and Rosen, 1958; LaBrosse, Axelrod and Kety, 1958; Leeper, Weissbach and Udenfriend, 1958) that MHMA represents, as shown in Fig. 1, the main end-product of the metabolism both of adrenaline and of noradrenaline. Urinary excretion of MHMA is not influenced by nutritional factors (Armstrong et al., 1957) and therefore permits an estimation of the endogenous catecholamine production.

Since catecholamines are produced in both the adrenal medulla and the adrenergic part of the vegetative nervous system, a raised MHMA excretion was expected and found not only in phaeochromocytomas (Armstrong et al., 1957; Bettex and Käser, 1962; Käser, Schweisguth, Sellei and Spengler, 1963; Robinson, Ratcliffe and Smith, 1959; Sandler and Ruthven, 1959; von Studnitz, 1960; von Studnitz and Hanson, 1959; Sunderman, Cleveland, Law and Sunderman, 1960) but in other tumours as well (Greenberg and Gardner, 1959; Käser, 1961a, b; Käser and Studnitz, 1961; Robinson et al., 1959; Sandler and Ruthven, 1959; Stickler, Hallenbeck and Flock, 1959; von Studnitz, 1960, 1961); it seemed promising to find out which tumours were associated with an increased MHMA excretion and how often the excretion in these tumours reached pathological levels.

\footnotetext{
* Paper read at a meeting of the British Association of Paediatric Surgeons in Sheffield, July 1963.

$\uparrow$ Supported by the Swiss National Fund for Scientific Research, Atomic Energy Commission.
}

We investigated about 150 children with a wide variety of tumours and found normal MHMA concentrations (3-9 $\mu \mathrm{g} . / \mathrm{mg}$. creatinine) in all patients with non-neural malignant tumours-mainly Wilms' tumours, reticulosarcomas and lymphosarcomas, retinoblastomas and stem-cell leukaemias, and in the six cases of ganglioneuroma observed until now (Fig. 2). On the other hand we saw an increase of MHMA not only in seven cases clinically simulating phaeochromocytoma but also in 45 out of 48 histologically proven neuroblastomas.

The determination of MHMA excretion, therefore, is a method of distinguishing phaeochromocytomas and neuroblastomas from non-neural malignancies as well as from other types of neural tumours in which raised MHMA values were found, i.e. in only a very few cases of ganglioneuromas having diarrhoea (Greenberg and Gardner, 1959; B. J. Rosenstein, 1962, personal communication; von Studnitz, Käser and Sjoerdsma, 1963). The differentiation between phaeochromocytomas and neuroblastomas, however, is not possible on this basis, and until recently it depended on the clinical symptomatology, the classical hypertension tests (e.g. histamine, regitine, dibenzyline) and the course. We now believe that, at least in certain cases, biochemical differences exist between neuroblastomas and phaeochromocytomas.

Fig. 3 shows three different chromatograms of urinary phenolic acids: Fig. $3 a$ is that of a normal subject, $3 b$ of a patient with neuroblastoma and $3 c$ of a patient with phaeochromocytoma. If we compare $3 \mathrm{a}$ with $3 \mathrm{c}$ we find a larger spot of MHMA on 3c. If we compare $3 a$ and $3 b$ we find not only a larger MHMA spot in $3 b$, but in addition a second spot that is considerably larger in $3 b$ than in $3 a$ and 3c. This latter substance could be identified as homovanillic acid (HVA = 3-methoxy-4-hydroxyphenylacetic acid), a common end-product of 'dopa' 


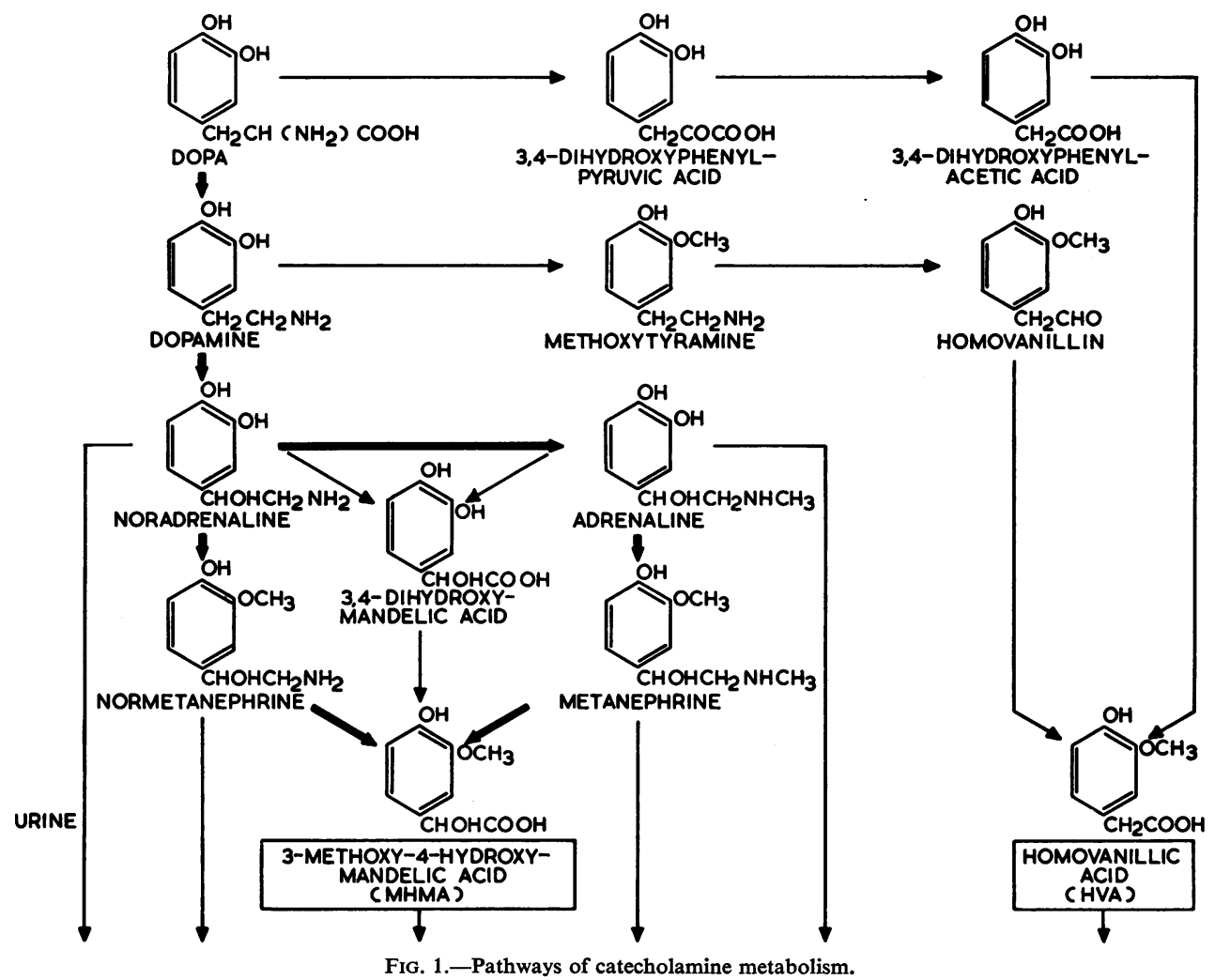

and 'dopamine' (Fig. 1), which is normally excreted in small amounts in the urine independently of dietary factors (Armstrong, Shaw and Wall, 1956; Axelrod et al., 1958; Shaw, McMillan and Armstrong, 1957).

Quantitative HVA determinations in a number of our tumour patients (Fig. 4) showed that the excretion remained normal $(5-40 \mu \mathrm{g} . / \mathrm{mg}$. creatinine) in all non-neural, malignant tumours as well as in our six ganglioneuromas. In 13 out of 16 neuroblastomas HVA concentrations were remarkably increased. On the other hand, compared with MHMA values, only 1 of 7 clinically obvious cases of phaeochromocytoma had a raised HVA excretion. This case showed other metabolic abnormalities and was finally found to have an atypical malignant hypernephroid and paraganglionic tumour of the adrenal gland. We may conclude, therefore, that there is frequently a significant increase in HVA excretion in neuroblastomas but never in phaeochromocytomas. These findings are similar to the observations of Robinson and Smith $(1960,1962)$ and of von Studnitz (1962). Quantitative HVA determinations can, therefore, be used as a further

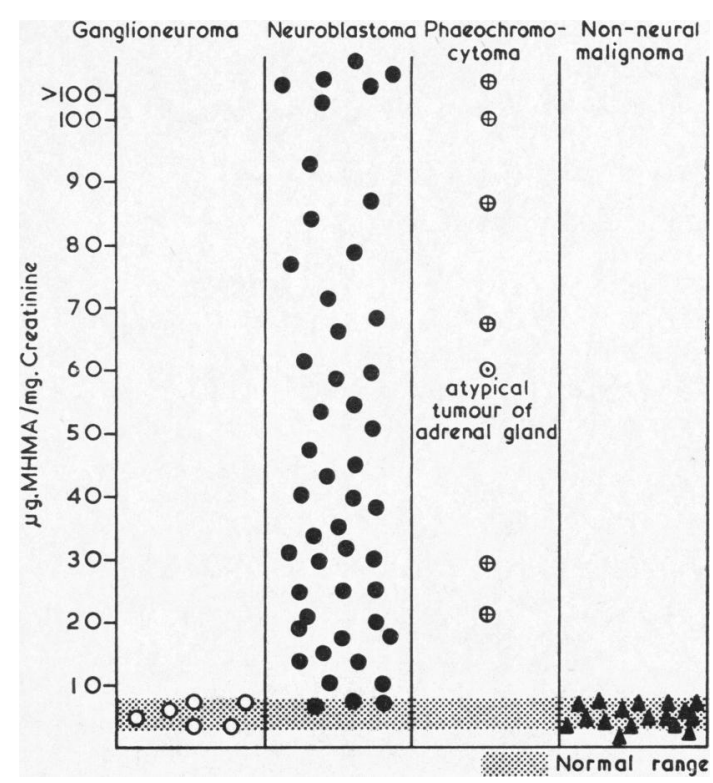

FIG. 2.-Urinary excretion of MHMA in various tumours. 
TABLE

URINARY EXCRETION OF CATECHOLAMINE METABOLITES IN 19 CASES OF NEUROBLASTOMA

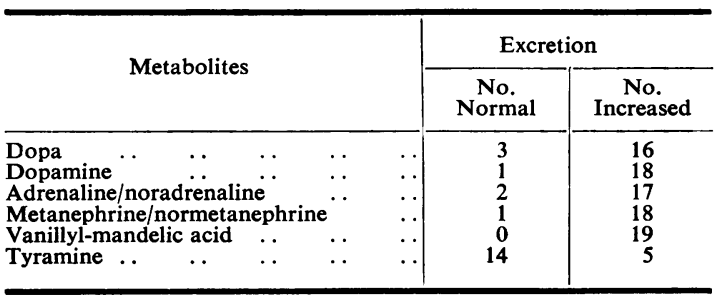

chemical criterion for the differentiation between these two tumours.

In an attempt to clarify the metabolic abnormalities observed in neuroblastomas we determined simultaneously, in collaboration with Dr. A. Sjoerdsma (von Studnitz et al., 1963), dopa, dopamine, adrenaline plus noradrenaline, metanephrine plus normetanephrine, vanillyl-mandelic acid and tyramine in some of our patients. Of 19 histologically

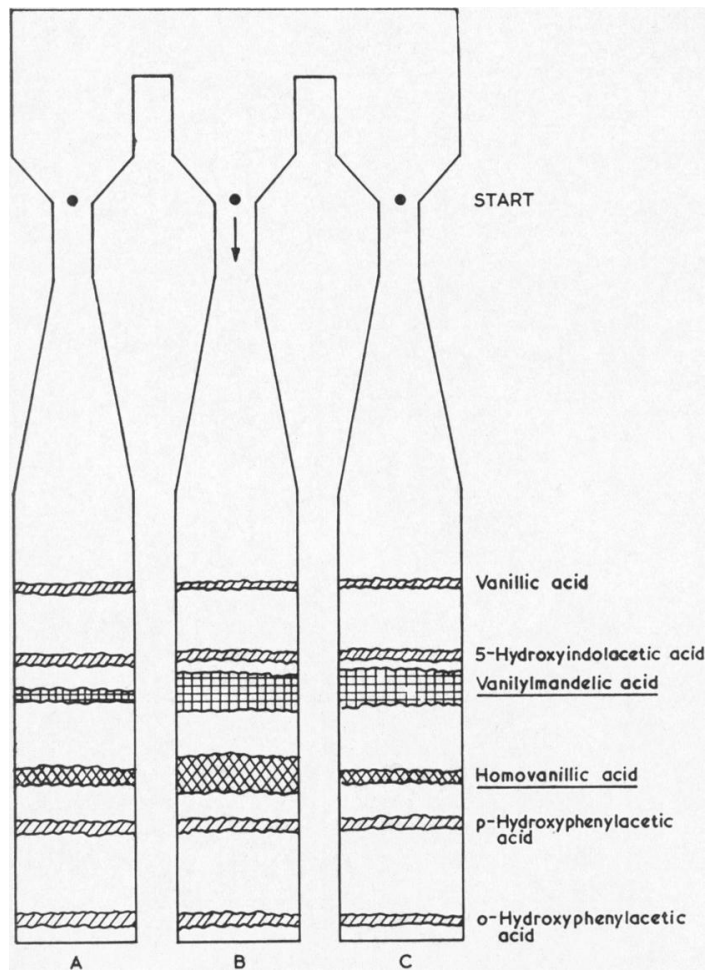

FIG. 3.-Chromatograms (schematically) of urinary phenolic acids of (a) a normal individual, (b) a patient with neuroblastoma and (c) a patient with phaeochromocytoma. confirmed neuroblastomas (Table) only $3 \mathrm{had}$ normal, whereas 16 had significantly increased dopa concentrations (expressed in $\mu \mathrm{g}$./mg. creatinine) in their urines. In 18 dopamine was increased, in 17 adrenaline plus noradrenaline and in 18 metanephrine plus normetanephrine. All had increased MHMA excretions but only 5 showed an increase of tyramine that exceeded the upper normal limit.

This demonstrates that patients with neuroblastomas are not only excreting larger amounts of MHMA and HVA, the main end-products on the one hand of adrenaline and noradrenaline, and on the other of dopa and dopamine, but that they must be associated with more profound disturbances in catecholamine metabolism. Even if one considers individual variations in the quantity of the metabolites excreted, the spectrum of the excreted products in neuroblastomas is characteristic enough to permit a differentiation from other tumours, e.g. from phaeochromocytomas which usually only show increased excretion of MHMA, noradrenaline or adrenaline and normetanephrine and metanephrine. At present we have no explanation for the biochemical abnormalities; they certainly have a differential diagnostic value and they might even give new prognostic and therapeutic clues in the future.

\section{Summary}

Some products of catecholamine metabolism were determined quantitatively in the urine of patients

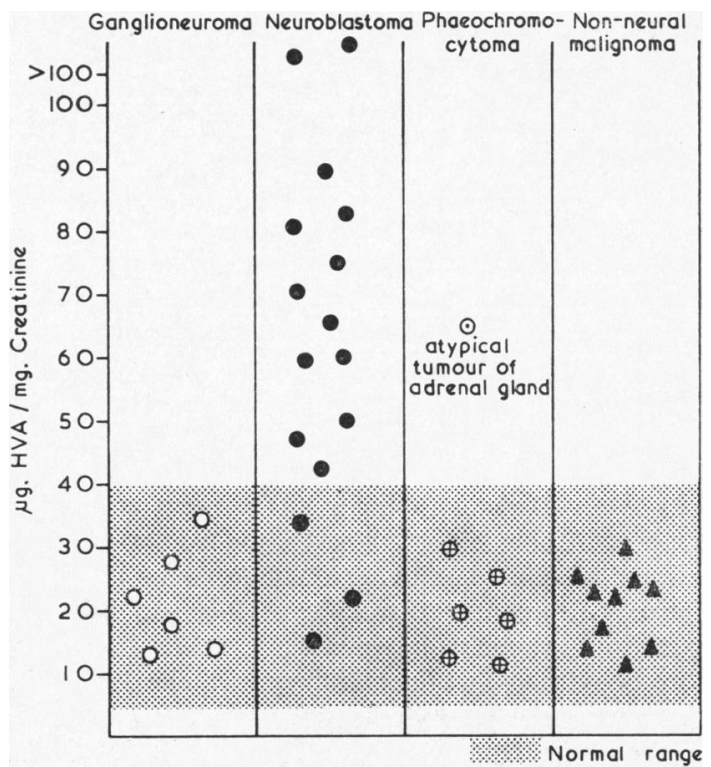

Fig. 4.-Urinary excretion of HVA in various tumours. 
with various tumours. No abnormalities could be found in non-neural malignant tumours and in the 6 ganglioneuromas examined. On the other hand, not only the phaeochromocytomas but 45 out of 48 neuroblastomas and a malignant hypernephroid and paraganglionic tumour of the adrenal gland showed increased vanillyl-mandelic acid excretion. In addition pathological homovanillic acid values were found in 13 of 16 neuroblastomas and in the atypical tumour, but never in the phaeochromocytomas. Finally investigations of 19 neuroblastomas revealed that in addition to the anomalies mentioned above and in contrast to other tumours, increased amounts of dopa, dopamine, noradrenaline and normetanephrine were frequently excreted. This observation is not only of theoretical interest but also has differential diagnostic value.

\section{REFERENCES}

Armstrong, M. D. and McMillan, A. (1957). Identification of a major urinary metabolite of norepinephrine. Fed. Proc., 16, 146. (1959). Studies on the formation of 3-methoxy-4-hydroxy D-mandelic acid, a urinary metabolite of norepinephrine and epinephrine. Pharmacol. Rev., 11, 394.

, - and Shaw, K. N. F. (1957). 3-methoxy-4-hydroxy-Dmandelic acid, a urinary metabolite of norepinephrine. Biochim.

biophys. Acta (Amst.), 25, 422. human urine. Paper chromatography of phenolic acids. J. biol Chem., 218, 293.

Axelrod, J., Inscoe, J. K., Senoh, S. and Witkop, B. (1958). Omethylation, the principal pathway for the metabolism of epinephrine and norepinephrine in the rat. Biochim. biophys. Acta (Amst.), 27, 210.

, Senoh, S. and Witkop, B. (1958). O-methylation of catechol amines in vivo. J. biol. Chem., 233, 697.

Bettex, M. and Käser, H. (1962). Diagnostic and prognostic value of the determination of urinary output of vanillyl-mandelic acid in tumours of sympathetic nervous system. Arch. Dis. Childh., 37, 138.

Greenberg, R. E. and Gardner, L. I. (1959). New diagnostic test for neural tumors of infancy: increased urinary excretion of 3 methoxy-4-hydroxymandelic acid and norepinephrine in ganglioneuroma with chronic diarrhea. Pediatrics, 26, 683.
Käser, H. (1961a). Elimination urinaire des produits de désintégration des catécholamines au cours des sympathoblastomes. Journées Pédiatriques, Paris, p. 203.

(1961b). Die Ausscheidung von Catecholaminmetaboliten im Urin bei Sympathicustumoren. Bull. schweiz. Akad. med. Wiss., $17,322$.

_. Schweisguth, O., Sellei, K. and Spengler, G. (1963). Die klinische Bedeutung der Bestimmung von Katechinaminkataboliten bei Tumoren. Helv. med. Acta., 30, 628.

- and Studnitz, W. von (1961). Urine of childrenwith sympathetic tumors. The excretion of 3-methoxy-4-hydroxymandelic acid. Amer. J. Dis. Child., 102, 199.

Kirshner, N., Goodall, McC. and Rosen, L. (1958). Metabolism of dl-adrenaline-2-Cl4 in the human. Proc. Soc. exp. Biol. (N.Y.), 98, 627.

LaBrosse, E. H., Axelrod, J. and Kety, S. S. (1958). O-methylation, the principal route of metabolism of epinephrine in man. Science, $128,593$.

Leeper, L. C., Weissbach, H. and Udenfriend, S. (1958). Studies on the metabolism of norepinephrine, epinephrine and their $o$-methy analogs by partially purified enzyme preparations. Arch. Biochem., 77, 417.

Robinson, R., Ratcliffe, J. and Smith, P. (1959). A screening test for phaeochromocytoma. J. clin. Path., 12, 541.

— and Smith, P. (1960). Urinary phenols in stress. Nature (Lond.), 186, 240. (1962). Uninary amines in phaeochromocytoma. Clin. chim. Acta., 7, 29.

Sandler, M. and Ruthven, C. R. J. (1959). Quantitative colorimetric method for estimation of 3-methoxy-4-hydroxymandelic acid in urine. Value in diagnosis of phaeochromocytoma. Lancet, 2 urine.

Shaw, K. N. F., McMillan, A. and Armstrong, M. D. (1957). The metabolism of 3,4-dihydroxyphenylalanine. J. biol. Chem., 226, 255.

Stickler, G. B., Hallenbeck, G. A. and Flock, E. V. (1959). Ganglioneuroblastoma associated with chronic diarrhea and increased excretion of catecholamines. Proc. Mayo Clin., 34, 548.

von Studnitz, W. (1960). Methodische und klinische Untersuchungen über die Ausscheidung der 3-Methoxy-4-Hydroxymandelsäure im Urin. Scand. J. clin. Lab. Invest., 12, Suppl. 48.

(1961). Neuroblastoma and catecholamine excretion. Lancet, 2, 215 .

(1962). Über die Ausscheidung der 3-Methoxy-4-hydroxyphenylessigsäure (Homovanillinsäure) beim Neuroblastom und anderen neuralen Tumoren. Klin. Wschr., 40, 163.

and Hanson, A. (1959). Determination of 3-methoxy-4 hydroxymandelic acid in urine by high-voltage paper electrophoresis. Scand. J. clin. Lab. Invest., 11, 101

, Käser, H. and Sjoerdsma, A. (1963). The spectrum of catecholamine biochemistry in patients with neuroblastoma. New Engl. J. Med., 269, 232.

Sunderman, F. W., Jr., Cleveland, P. D., Law, N. C. and Sunderman, F. W. (1960). A method for the determination of 3-methoxy-4 hydroxymandelic acid ('vanilmandelic acid') for the diagnosis of pheochromocytoma. Amer. J. clin. Path., 34, 293. 